\title{
Collaboration and Cooperation: A Case Study of Two Students' Coursework in A Canadian Secondary School
}

\author{
Xingzuo Zhou ${ }^{1, *}$ \\ ${ }^{1}$ Department of Economics, University College London, London, United Kingdom \\ *Corresponding author: E-mail: xingzuo.zhou.19@ucl.ac.uk
}

\begin{abstract}
Since the outbreak of the COVID-19 pandemic, online teaching has been largely implemented. Schools, teachers and educators must understand the significance of communications among students during online teaching, and one way to encourage more collaboration is to assign group coursework. Higher contribution in group coursework from students indicates more collaboration among students. In order to find a way to encourage higher contribution, this study tested different grouping methods: random grouping and regrouping, grouping with similar ability, free grouping and free grouping with a penalty applied to non-contributor. Random regrouping did not have a significant impact on contribution; ability grouping had a positive effect on contribution; friendship was observed to be a negative factor in contribution when grouping and penalty applied also did not work with friendship. Due to this result, this study suggested schools and educators allocate students with similar ability together when grouping. In this way, a higher contribution is encouraged, and group coursework can play its role.
\end{abstract}

Keywords: Behavioral economics, Experimental economics, School policy, Cooperation, Decision

\section{INTRODUCTION}

Since the outbreak of COVID-19 pandemic, social distancing was proved to be effective in preventing the spread of virus [1]. As a result, online teaching through platforms such as Zoom and Microsoft Teams was applied to counteract the impact of COVID-19 pandemic [2]. However, a problem arose: due to the nature of online teaching, students cannot communicate freely as they were in the past. Therefore, encouraging online collaboration among students is significant during this special period.

Before COVID-19 pandemic, some scholars had been on research to identify the impacts of online teaching. Tomei tried to find the optimal class size that ensured the quality of teaching [3]; Bender identified the significance of discussions in online teaching [4]. As COVID-19 pandemic arrived, online teaching was forced to be largely implemented, and to encourage discussions was then a significant matter. There were many studies discussing the measures that encourage collaboration. Kozar identified the relationship between group work and cooperation and collaboration [5], and Burke suggested using groups more effectively so that cooperation and collaboration were better promoted [6]. In short, it is significant to manage groups such that the cooperation and collaboration between students are encouraged to the maximum; only in this way, group work can play a role.

To find the factors influencing the degree of cooperation, David and Holt firstly discovered the declined and low cooperation among humans, ceteris paribus[7]. Davies, Hallam and Ireson discussed the impact on students if grouping them based on their ability[8]. In their experiment, students were highly motivated because of the potential threat to allocate them to groups with lower ability. J. Kulik and C. Kulik also discovered similar results[9]. Students generally performed better with ability grouping on student achievement. Researchers also studied some other types of grouping, such as grouping with friends. Chen and Rau discovered that within a group, if members had a stronger relationship, directive leadership was anticipated to be observed with a higher probability[10]. In other words, the partition of contribution might be extremely unequal. Apart from grouping methods, Fehr and Gächter also proposed punishment applied to individuals who contributed less than others[11]. In their 
study, higher cooperation was observed with punishment, with random grouping.

Despite those efforts, there is no study to combine cooperation and school coursework together, with realistic settings. In addition, unlike the setting of public goods, many students know each other so that random grouping is likely to be "not random". In other words, even with random grouping, students are likely to know each other. Hence, the punishment applied in public good games may not function well in this coursework setting. It is necessary to test the function of punishment if group members are friends.

In this study, the author plans to test students' collaboration and cooperation in their group coursework. The grouping methods will include random grouping, ability grouping, friendship grouping and friendship grouping with a penalty applied.

\section{MATERIALS AND METHODS}

\subsection{Source of Data}

The data obtained is based on an experiment conducted in August. The subjects of the experiment are senior students from Canadian secondary schools and all students consent to participate in the experiment voluntarily. This study focused on 2-student coursework. To simulate real-life school coursework, students were given 1.5-hour lecture before each coursework; and \$5 is awarded to the student who achieved the highest grades across all the work. Each coursework was consisted of 5 questions, and after they completed the coursework, they were asked to fill in a survey that records their contribution. As figure 1 demonstrated, they were required to fill in "c" if they contributed to that question. In the end, their contribution of each coursework was calculated based on the surveys: if Bob contributed to 5 questions, then his contribution is 5 out 5 , which is $100 \%$; if Emma contributed to 0 question, then her contribution is 0 out 5 , which is $0 \%$.

In addition, during the experiments, students were allowed to search online and seek help from the author regarding any questions of the coursework. Therefore, in this setting, students were able to have all work done if they wanted to contribute.

\begin{tabular}{|l|l|l|}
\hline Type “c" if contributed & Member 1: Bob & Member 2: Emma \\
\hline Q1 & c & \\
\hline Q2 & c & \\
\hline Q3 & c & \\
\hline Q4 & c & \\
\hline Q5 & c & \\
\hline
\end{tabular}

Figure 1 Survey example

\subsection{Design of Experiment}

There were 5 "trials" in total, namely 5 pieces of group coursework in total. For each piece of group coursework, all students were placed in a group of two, where groups were formed with different conditions. As mentioned, before each trial, students were given 1.5hour lecture; after the trial, coursework was assigned, and all groups were asked to fill in a survey that collected their contribution in each coursework.

\subsubsection{Trial \#1}

In the first trial, students were given a lecture that mentioned derivatives, correlation, covariance, confidence interval and hypothesis testing. After the lecture, students were grouped randomly by two, and the first simulated coursework was consisted of 5 questions that asked students to calculate derivatives, covariance and confidence interval.

\subsubsection{Trial \#2}

In the second trial, students were given a lecture that mentioned assumptions and derivations of Ordinary Least Square (OLS) estimators. After the lecture, students were re-grouped randomly by two, and the second simulated coursework was consisted of 5 questions that asked students to list derive OLS estimators and tested assumptions of OLS estimators.

\subsubsection{Trial \#3}

In the third trial, students were given a lecture that mentioned applications and statistical inferences of OLS estimators. After the lecture, groups were re-formed based on students' ability. Specifically, students with similar grades in the first two coursework were placed together. The third simulated coursework was consisted of 5 questions that asked students to test the significance of estimators. 


\subsubsection{Trial \#4}

In the fourth trial, students were given a lecture that mentioned how to use STATA. After the lecture, groups were re-formed freely, that is, students were allowed to choose their own groupmates. The fourth simulated coursework was consisted of 5 questions that asked students to practice data analysis with STATA.

\subsubsection{Trial \#5}

In the fifth trial, students were given a lecture that mentioned how to use LaTeX. After the lecture, groups were kept being the same as in the fourth trial, but students were able to give a penalty (deduction of grades in 5th coursework) to their groupmates if students believe that their groupmates do not contribute fairly. The fifth simulated coursework was consisted of 5 questions that asked students to practice typing with LaTeX.

\section{RESULTS}

\section{Contribution}

$100 \%$

$75 \%$

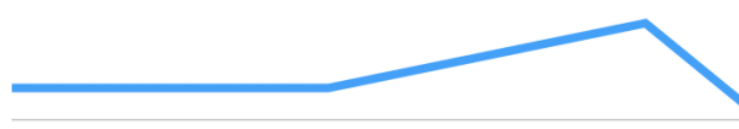

\section{$50 \%$}

\section{$25 \%$}

\section{$0 \%$} 1
2

Figure 2 Median contribution in five trials
Figure two graphically shows the median of contribution in 5 trials. As the size of this research is relatively small, exposing data publicly may result in violating participants' privacy. Hence, participants of this study did not agree for their data to be shared publicly, so specific supporting data is not available, and the median contribution is illustrated instead. The vertical axis shows the median contribution from $0 \%$ to $100 \%$ and the horizontal axis shows the number of trials. As observed, students' choice of contribution did not change between trial \#1 and trial \#2, it stayed constant at $80 \%$. As in trial \#3, median contribution was raised to $90 \%$. Eventually, in trial \#4 and trial \#5, the choice of contributions declined to $50 \%$.

\section{DISCUSSION}

In trial \#1, the groups were formed randomly. The median contribution, $80 \%$, illustrated students' initial choice of contribution and trust.

In trial \#2, the groups were reformed randomly as well. Therefore, any difference in contribution between those two trials illustrated students' behaviors in "onetime repeated game". With traditional theory, we expected a decline in contribution. However, in our experiment, the median contribution did not change. Therefore, we might conclude that students would not behave differently while time passes. We will assume that there is no impact on contribution as the experiment continues due to this finding.

In trial \#3, the higher median contribution was observed when students with similar ability were assigned together. It could be explained by the reason that students were "forced" to contribute more as their partners do not have a much stronger ability to let them "free ride" [12].

In trial \#4, students were allowed to choose their partners. In this trial, we observed a dramatic decline in contribution. A possible reason could be that two group members knew each other. Student with stronger ability contributed more as he/she believed more effort from his/her partner is needed, which was inefficient and took more time. 
In trial \# 5, the same groups were kept, but students could levy a penalty on their partners if they felt their partners had not contributed sufficiently. From traditional theory, we expected higher contribution. However, same median contribution was observed. A possible reason could be the friendship. Since students did not want to harm their friendship with their partners and they might be embarrassed if they give penalty to their friends, students eventually chose not to give penalty to their friends, which led to the same contribution in trial \#4.

Indeed, some limitations existed. Although our sample size is one standard Canadian high school class, eight students might be still small. In addition, the experiment is a simulation, but not real coursework which may affect one's GPA and therefore the whole life. Using the theory of intertemporal utility, they may behave differently as their contribution may have higher return of utility.

\section{CONCLUSION}

From the experiment, the author suggests the following procedure in assigning group coursework so that cooperation and collaboration are encouraged: when assigning groups, students with similar grades are suggested to be placed together; when assigning groups, students with better relationship are suggested to be separated.

Through those two suggested procedures, more collaboration is anticipated, and therefore the shortcoming of online teaching during COVID-19 pandemic - the lack of communications, is lessened. Despite some limitations, this study helped schools to lessen the impact of COVID-19 pandemic by encouraging more collaboration between students. In future studies, the author plans to expand the scale of experiment, and may request permission from schools to conduct the experiment in credit course. In this way, the study may present more precise findings. As so-called blended teaching has been popular, it is essential for the schools to encourage collaborations while providing online teaching. It is possible to measure collaboration in face-to-face teaching and compare it in online teaching together so that collaboration among students is better studied.

\section{ACKNOWLEDGMENT}

The author appreciates Prof. Louis Putterman from Brown University and Yufan Huang for their helpful suggestions.

\section{REFERENCES}

[1]. Greenstone, M., \& Nigam, V. (2020). Does Social Distancing Matter? University of Chicago, Becker
Friedman Institute for Economics Working Paper. No. 2020-26. doi: 10.2139/ssrn.3561244

[2]. Greenhow, C., \& Chapman, A. (2020). Social distancing meet social media: digital tools for connecting students, teachers, and citizens in an emergency. Information And Learning Sciences, 121(5/6), 341-352. doi: 10.1108/ils-042020-0134

[3]. Tomei, L., \& Nelson, D. (2019). The Impact of Online Teaching on Faculty Load Revisited. International Journal Of Online Pedagogy And Course Design, 9(3), 1-12. doi: 10.4018/ijopcd.2019070101

[4]. Bender, T. (2012). Discussion-based online teaching to enhance student learning. Stylys.

[5]. Kozar, O. (2010). Towards Better Group Work: Seeing the Difference between Cooperation and Collaboration. English Teaching Forum, 48(2), 1623. https://eric.ed.gov/?id=EJ914888

[6]. Burke, A. (2011). Group Work: How to Use Groups Effectively. Journal of Effective Teaching, 11(2), 87-95. https://eric.ed.gov/?id=EJ1092109

[7]. Davis, D., \& Holt, C. (1999). Equilibrium cooperation in two-stage games: Experimental evidence. International Journal Of Game Theory, 28(1), 89-109. doi: $10.1007 / \mathrm{s} 001820050100$

[8]. Davies, J., Hallam, S., \& Ireson, J. (2003). Ability groupings in the primary school: issues arising from practice. Research Papers in Education, 18(1), 45 60. doi: 10.1080/0267152032000048578

[9]. Kulikand, J., \& Kulik, C. (1987). Effects of Ability Grouping on Student Achievement. Equity \& Excellence In Education, 23(1-2), 22-30. doi: $10.1080 / 1066568870230105$

[10]. Chen, N., \& Rau, P. (2017). Cooperation with friends or new encounters: Tie strength and shared leadership behaviors. Social Behavior And Personality: An International Journal, 45(4), 573582. doi: $10.2224 / \mathrm{sbp} .5868$

[11]. Fehr, E., \& Gächter, S. (2000). Cooperation and Punishment in Public Goods Experiments. American Economic Review, 90(4), 980-994. doi: 10.1257/aer.90.4.980

[12]. Ireson, J., Hallam, S., \& Hurley, C. (2013). What are the effects of ability grouping on GCSE attainment? British Educational Research Journal, 31(4), 443-458. doi: 10.1080/01411920500 148663 